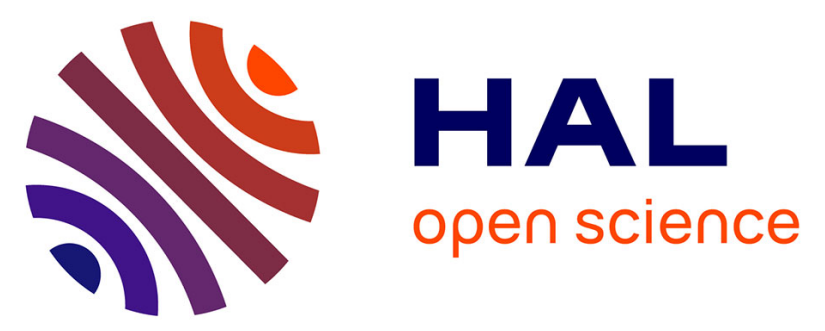

\title{
A new design of an air core transformer for Electric Vehicle On-Board Charger
}

\author{
Valentin Rigot, Tanguy Phulpin, Daniel Sadarnac, Jihen Sakly
}

\section{To cite this version:}

Valentin Rigot, Tanguy Phulpin, Daniel Sadarnac, Jihen Sakly. A new design of an air core transformer for Electric Vehicle On-Board Charger. 2020 22nd European Conference on Power Electronics and Applications (EPE'20 ECCE Europe), Sep 2020, Lyon, France. pp.1-9, 10.23919/EPE20ECCEEurope43536.2020.9215632 . hal-03280745

\section{HAL Id: hal-03280745 \\ https://hal.sorbonne-universite.fr/hal-03280745}

Submitted on 23 Jul 2021

HAL is a multi-disciplinary open access archive for the deposit and dissemination of scientific research documents, whether they are published or not. The documents may come from teaching and research institutions in France or abroad, or from public or private research centers.
L'archive ouverte pluridisciplinaire HAL, est destinée au dépôt et à la diffusion de documents scientifiques de niveau recherche, publiés ou non, émanant des établissements d'enseignement et de recherche français ou étrangers, des laboratoires publics ou privés. 


\title{
A new design of an air core transformer for Electric Vehicle On-Board Charger
}

\author{
First preferred Subtopic: $1 . \mathrm{a}$ \\ Origin: $\quad$ University-Industry (U-I) \\ Preference of Presentation: \\ Second preferred Subtopic: $8 . \mathrm{b}$ \\ Dialogue (Poster)
}

\section{Keywords}

«Passive component», «transformer», «coreless», «electric vehicle», «on board charger».

\begin{abstract}
The paper focuses on air core transformer and a comparison between different geometries is presented. Coreless transformer is relevant for high frequency converters, allowing the size reduction. The efficiency is a key parameter on power electronic and a trade off as to be chosen between size and efficiency. The proposed structure will permit to increase the converter power density
\end{abstract}

\section{Introduction}

The autonomy of electric vehicles is a key challenge for electrical vehicle and each part of the electrical power architecture must be optimized by reducing its size and weight [1]. For this purpose, active devices development such as $\mathrm{GaN}$ and $\mathrm{SiC}$ allows to increase the power converter's switching frequency which lead to increase the power density by reducing the size of passive devices [2]. However, these passive components still present the biggest part of the converter in term of volume [3], They also limit the efficiency at high frequency because of the eddy effect and the copper losses [4]. Thus, investigate the passive components and specifically the coreless magnetics components is relevant on-board battery charger development.

\section{Air core transformer}

Generally, air core transformers are used in very limited application for inductive charge, superconductor, medical scanner or magnetic sensors [5]. Without magnetic material, turns of coil emits a magnetic field in its environment. For isolated converter, it is necessary to canalize the magnetic field in order to get a good coupling coefficient. As presented by eq (1), the coupling coefficient expression in the transformer depends on transmitted magnetic flux from its primary to its secondary. Thus, drive the magnetic field becomes crucial for the efficiency of our converter.

Moreover, as shown by eq (2), the inductance value of the transformer depends on the core magnetic permeability. A weak permeability as air permeability induces a weak inductance value. For power converter design, the voltage is commonly imposed, and a lower inductance leads to a higher current as expressed by the following eq (3) and eq (4). The use of air core transformer is relevant for high frequency or low voltage applications. On the other hand, low permeability of the air core induces more magnetic field leakage. The only solution is to minimize the magnetic field outside of the transformer by appropriate adjustment of coil's turns.

$$
k=\frac{\varphi_{12}}{i_{1}}
$$

Where $\varphi_{12}$ and $i_{1}$ are, respectively, magnetic flux and primary current.

$$
L=\frac{n^{2} \mu S_{e}}{l_{e}}
$$

Where $n$ is the turns ratio, $\mu$ is the permeability, $S_{e}$ is the equivalent section and $l_{e}$ is the equivalent length.

$$
u=U \sin (\omega t)=L \frac{d i}{d t}
$$




$$
i=-\frac{U}{\omega L} \cos (\omega t)
$$

\section{Field canalization by superposition theorem}

For improving the design of an air core transformer, it is important to avoid magnetic field. Superposition theorem could be a good solution. The result of the contribution of all coil turns is the sum of results of each coil turns contribution.

With this method, magnetic field produced by one coil turn is balanced by another coil turn as in fig.1a. But as shown by simulation with Finite Element Method by FEMM, magnetic field is still spreading. We can use symmetry properties and add other turn to balance the magnetic field as fig. $1 \mathrm{~b}$. The best solution is to add coil turns until reaching continuous turns around a revolution symmetric axis of the transformer, meaning that the toroidal geometry is the suitable choice in this case as shown by Fig.1c.

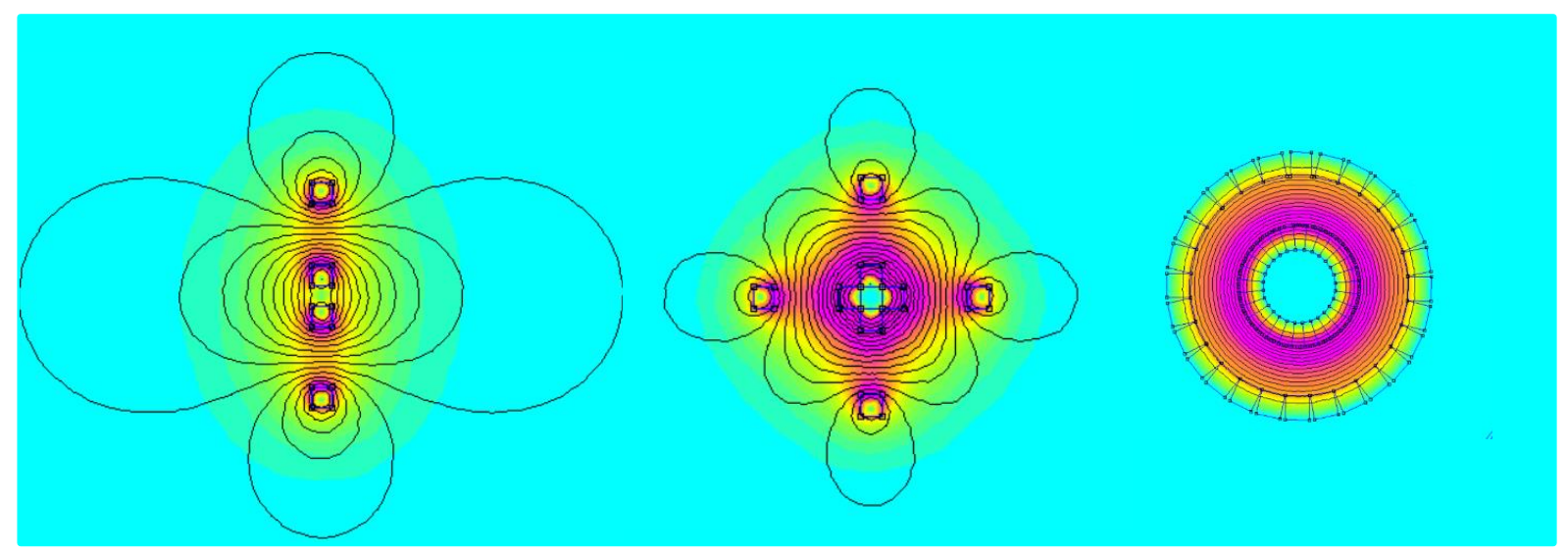

(a)

(b)

(c)

Fig. 1: compensation of magnetic radiation by superposition method: (a) two coil turns, (b) four coil turns, (c) toroidal geometry

But this geometry is difficult to perfectly realize because of difference between inside and outside radius. If the turn number in the inside radius create a continuous conductor circle, it will create some holes in the outside circle. That's why we propose to double the thickness of the inside circle and to choose an outside radius twice longer. Consequently, we can obtain mostly continuous conductor inside and outside the transformer. For the second winding, four layers in the inside circle are needed to keep continuous conductor. A lot of wire is hence required generating more losses, heaviness and volume [6].

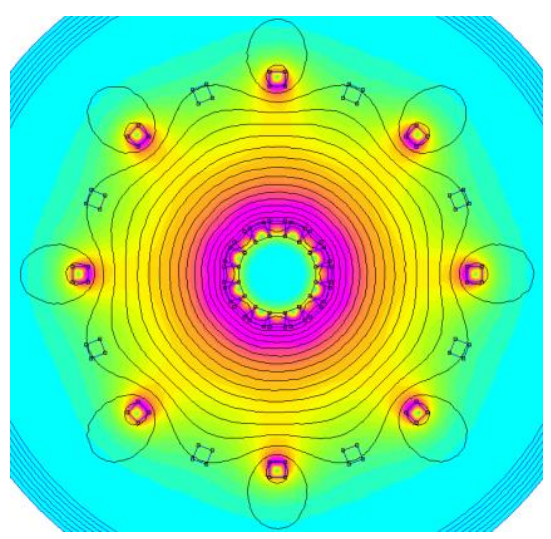

(a)

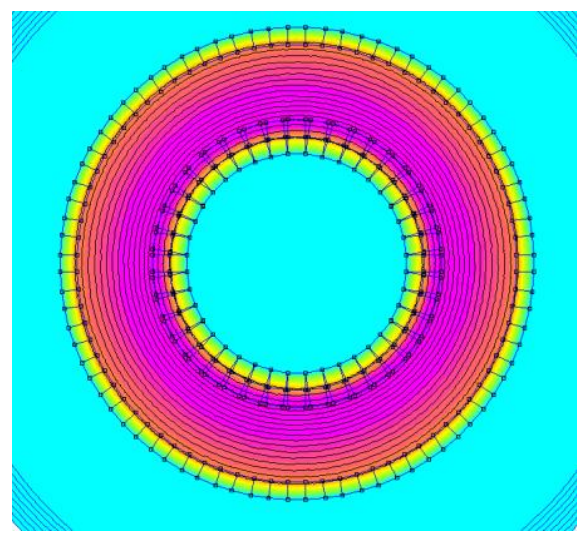

(b)

Fig. 2: Toroidal transformers: (a) common transformer (b) proposed transformer 
Moreover, realization of this kind of transformer is manual and difficult because there are few empty spaces. It's necessary to pull in and pull out wires like a sewing technique and requires manual interventions. The equation (5) shows the method to compute self-inductance in a toroid transformer [7]

$$
L=\frac{n \varphi}{i}=\frac{n^{2} H}{2 \pi} \ln \left(\frac{R_{\text {out }}}{R_{\text {in }}}\right)
$$

In our case, we choose the outside radius $R_{\text {out }}$ twice longer than the inside radius $R_{\text {in }}$ and the height $H$, the equation (5) becomes the equation (6)

$$
L=\frac{n^{2} R}{2 \pi} \ln (2)
$$

\section{Proposed air core transformer}

Because of the difficulties related to the toroidal transformer manufacturing, we design a transformer achievable in holding only once the wires with as main. Objective to keep the lowest leakage magnetic field. Second goal is to obtain a good coupling coefficient, in order to easily transmit the power. Usually, solenoids are used, because of manufacturing issues but the magnetic field is not totally canalized. Indeed, its main part spreads above and below the solenoid. That's why the idea was to complete this geometry by adding turns in opposite direction. As expected, it reduces drastically the leakage magnetic field as represented in figure 4(b). To go further, it's possible to add opposite turns also at each side of the transformer as in figure 4(c). We compute magnetic field at $5 \mathrm{~cm}$ from the center of the transformer by Finite Element method. Moreover, volume occupied by each geometry and selfinductance of the first coil in each case by the Biot \& Savart law was calculated. It shows that the magnetic field is finally well canalized, and the field lines looks like if there was a magnetic core. The outside magnetic field is drastically reduced by more than 300 times.

Table I: Results and magnetic radiation for air core transformers

\begin{tabular}{|l|l|l|}
\hline Simple solenoid transformer & $\begin{array}{l}\text { Solenoid transformer with turn added } \\
\text { above and below }\end{array}$ & Transformer developed \\
\hline & & \\
\hline $16,79 \mu \mathrm{H}$ & $16,77 \mu \mathrm{H}$ & $14,22 \mu \mathrm{H}$ \\
\hline $7,12 \mathrm{mT}$ & $0,13 \mathrm{mT}$ & $0,02 \mathrm{mT}$ \\
\hline $0,02 \mathrm{~L}$ & $0,05 \mathrm{~L}$ & $0,10 \mathrm{~L}$ \\
\hline
\end{tabular}

\section{Comparison and possible applications of two transformers}

We created two prototypes of air core transformers according to the best toroid selection and to the new geometry proposed in order to compare them. The toroid transformer was designed to reach $7,8 \mu \mathrm{H}$ following the eq (6) and a Finite element method computed a self-inductance of $11 \mu \mathrm{H}$. The toroid transformer support was manufactured, 
and the cylindrical transformer support was 3D printed in order to be ventilated. The model for the 3D printing is shown Fig.3a. Both realized prototypes can be viewed Fig.3b and Fig.3c. Values were calculated by finite element method and verified by experimental measurement with an RLC meter during short-circuit and open-circuit tests. The test bench can be viewed Fig.5

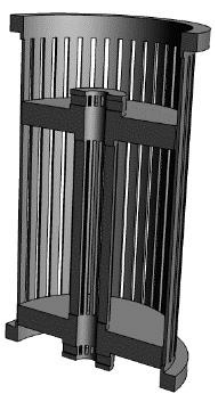

(a)

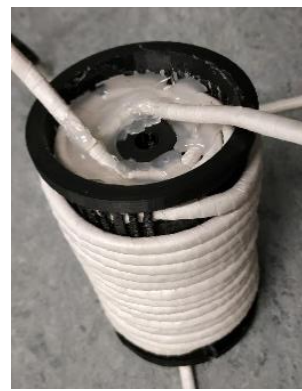

(b)

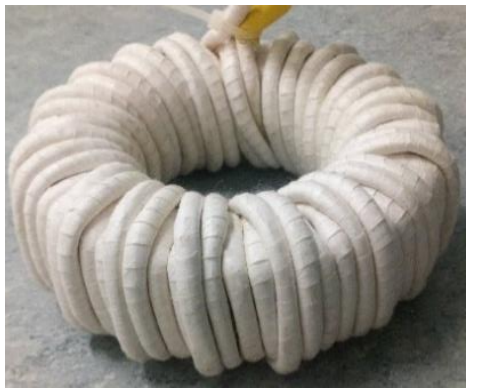

(c)

Fig. 3: Air core transformer: (a) model (b) cylindric prototype (c) toroidal prototype

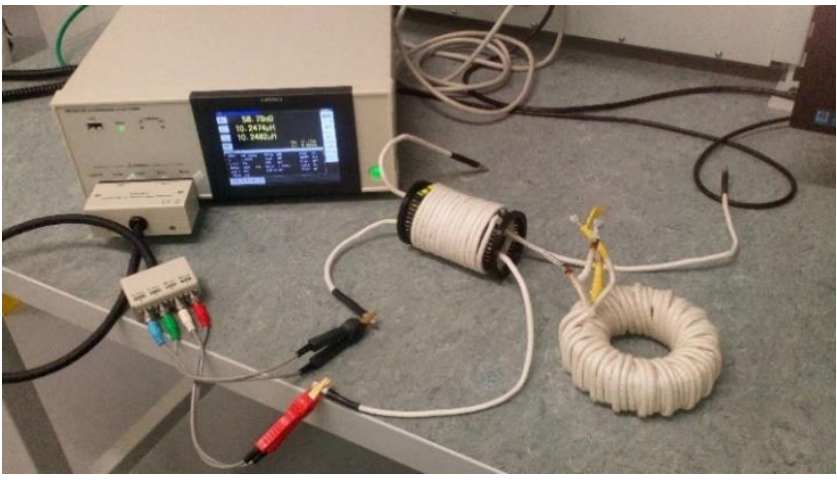

Fig. 3: test bench for air core transformer

We compute the results in table 2 .

Table II: Characteristics of two air core transformers

\begin{tabular}{|c|c|c|c|c|c|c|c|c|c|c|c|c|c|c|}
\hline & \multicolumn{3}{|c|}{$100 \mathrm{kHz}$} & \multicolumn{3}{|c|}{$500 \mathrm{kHz}$} & \multicolumn{3}{|c|}{$1 \mathrm{MHz}$} & \multicolumn{3}{|c|}{$2 \mathrm{MHz}$} & \multirow[t]{2}{*}{ Volume } & \multirow[t]{2}{*}{ Weight } \\
\hline & $\begin{array}{l}L \\
(\mu H)\end{array}$ & $\begin{array}{l}L f \\
(\mu H)\end{array}$ & $\begin{array}{l}R \\
(\mathrm{mOhms})\end{array}$ & $L$ & $L f$ & $R$ & $L$ & $L f$ & $R$ & $L$ & $L f$ & $R$ & & \\
\hline $\begin{array}{l}\text { Proposed } \\
\text { toroid }\end{array}$ & 4,8 & 1,13 & 23 & 4,89 & 1,09 & 135 & 4,9 & 1,09 & 449 & 5,04 & 1,05 & 1410 & 0,48 & 0,88 \\
\hline $\begin{array}{l}\text { Proposed } \\
\text { cylindric }\end{array}$ & 10,35 & 1,9 & 26 & 10,3 & 1,87 & 160 & 10,26 & 1,89 & 545 & 10,1 & 1,8 & 1700 & 0,26 & 0,84 \\
\hline
\end{tabular}

First, we note that toroidal transformer presents worst results than expected. This is due to the winding complexity, where the exact number of turns wasn't reached. Concerning the comparison, the new geometry is twice smaller, and its self-inductance $L$ is twice bigger. That can be resumed as a four times better self-inductance by volume unit. The leakage inductance $L f$ is fewer in the cylindric transformer but the coupling coefficient stays equivalent (respectively $77 \%$ and $81 \%$ on average). We can notice that the resistance $R$ is high for both transformers at frequencies exceeding $100 \mathrm{kHz}$ because of the quality of the Litz wire used which were initially design for $100 \mathrm{kHz}$ maximum operating point.

\section{Conclusion}

This article proposes a study and a comparison of different geometry of coreless transformer. It presents an easier method to produce a transformer keeping an equivalent coupling coefficient as a toroidal transformer. Moreover, it proposes a prototype with better value for power density twice smaller. However, we notice the difficulty of simulation and design realization because any analytics techniques are yet developed. Next step will be to compare the magnetic field emitted around each transformer and to optimize the coil turns position for the cylindrical transformer. 


\title{
References
}

[1] Khaligh A., Antonio M.D. : Global Trends in High-Power On-Board Chargers for Electric Vehicles, vol. 9545, no. c, 2019

[2] Taurou E. : Utilisation des transistors GaN dans les chargeurs de véhicule électrique, HAL Id : tel-01945931, 2018.

[3] Meyer P., Perriard,Y. : Skin and Proximity Effects for Coreless Transformers, Conf. Electr. Mach. Syst., vol. 1 , no. 3, pp. 1-5, 2000.

[4] Kazimierczuk M.K. : Winding Resistance and Power Loss of Inductors with Litz and Solid-Round Wires, IEEE Trans. Ind. Appl., vol. 54, no. 4, pp. 3548-3557, 2018.

[5] Kim T. : 3D Printed Flexible Coreless Transformers, Internationnal Flexible Electronics Technology Conference (IFETC), 2018

[7] Sadarnac D. : Du composant magnétique à l'électronique de puissance - Analyse, modélisation, conception, dimensionnement des transformateurs, inductances, convertisseurs - Cours et exercices corrigés, Éditions Ellipses. 2014

[6] Nigam M., Sullivan C.R. : Multi-layer folded high-frequency toroidal inductor winding, IEEE Applied Power Electronics Conference,pp. 682-688, Feb. 2008

\author{
Valentin Rigot \\ VEDECOM, Versailles, France \\ Tanguy Phulpin \\ Sorbonne University, CNRS, Group of electrical engineering - Paris, Paris, France \\ Daniel Sadarnac \\ Sorbonne University, CNRS, Group of electrical engineering - Paris, Paris, France \\ Jihen Sakly \\ VEDECOM, Versailles, France
}

